\title{
Technical note: The use of an accelerometer for measuring step activity and lying behaviors in dairy calves
}

\author{
T. H. Swartz, M. L. McGilliard, and C. S. Petersson-Wolfe ${ }^{1}$ \\ Department of Dairy Science, Virginia Tech, Blacksburg 24061
}

\section{ABSTRACT}

Calf behaviors such as step activity, lying bouts, and lying time may be an indicator of calf health and welfare. To reduce time-consuming visual observations, the use of behavioral monitoring systems have been developed to capture these data. Previous studies have validated lying behaviors using an accelerometer (HPG; HOBO Pendant G data logger, Onset Computer Corp., Bourne, MA) in calves. However, the HPG does not measure step activity. The objectives of this study were to (1) validate step activity, lying bouts, and lying time of AfiTag II (AT2; AfiTag II, Afimilk Ltd., Kibbutz Afikim, Israel) to observations from video, and (2) to compare the behavioral data from AT2 to the HPG. Calves $(\mathrm{n}=5)$ were group housed with an automatic calf feeder. Video cameras were installed at both sides of the pen, and observations were analyzed for $7 \mathrm{~h} /$ calf. The AT2 and the HPG were both attached to the lateral side of the right rear leg of 5 calves, and data were recorded for $10 \mathrm{~d}$. The full 10-d data set was used to examine correlations for lying bouts and lying time between AT2 and the HPG. The HPG was set at a 60-s sampling interval and the output was analyzed both unfiltered as well as utilizing a 1-min event filter to remove potentially erroneous readings. The AT2 recorded step activity, lying bouts, and lying time, and summarized these behaviors in 15 -min periods. The AT2 recorded lying time in 3-min intervals, which were then automatically summarized in 15-min periods. The correlations of step activity, lying bouts, and lying time between video recordings and AT2 were 0.99. For the second objective, correlations between AT2 and the HPG were 0.99 for lying time and 0.93 for lying bouts. The 1-min event filter resulted in a 0.03 improvement in correlations for lying bouts between the HPG and AT2. The high correlation between video recordings and AT2

Received April 9, 2016.

Accepted July 29, 2016.

${ }^{1}$ Corresponding author: cspw@vt.edu suggest that this device can be used to measure step activity, lying time, and lying bouts in unweaned dairy calves housed in groups.

Key words: validation, calf, lying behavior, activity

\section{Technical Note}

As herd size continues to increase in the dairy industry, many producers have turned to technology to assist with daily management tasks (Khanal et al., 2010). Triaxial accelerometers have grown in popularity in part due to their usefulness in estrus detection (Dolecheck et al., 2015), but more recently research has shown value in disease detection (Alsaaod et al., 2012; Fogsgaard et al., 2015; Itle et al., 2015). In dairy cattle, accelerometers have been used to detect behavioral changes around calving and disease events (Alsaaod et al., 2012; Jensen, 2012; Fogsgaard et al., 2015; Itle et al., 2015). Early detection of these events can allow for timely intervention, potentially reducing the negative effect on the cow. In dry cows, a significant increase in standing times either during the week before calving or on the day of calving was indicative of clinical ketosis (Itle et al., 2015). In addition, cows close to calving showed an increase in step activity and lying bouts $6 \mathrm{~h}$ before calving and a decrease in lying time $24 \mathrm{~h}$ before calving, allowing for the development of calving alerts (Jensen, 2012). Furthermore, lameness in lactating dairy cattle housed in freestalls can be found with $76 \%$ accuracy utilizing deviations from a baseline for lying behaviors and step activity (Alsaaod et al., 2012). Lastly, mastitic cows were more restless for $10 \mathrm{~d}$ after initial infection date, exhibiting an increased frequency in lying bouts and step activity, and decreased lying time (Fogsgaard et al., 2015).

Research in calves has shown promise in identifying disease through behavioral changes. When low doses of Escherichia coli endotoxin (0.025 or $0.05 \mu \mathrm{g}$ of LPS/ $\mathrm{kg}$ of $\mathrm{BW}$ ) were injected IV, calves were less active while lying, and total lying time was unaffected (Borderas et al., 2008). In another study, calves inoculated with Mannheimia haemolytica to experimentally induce pneumonia showed a significant decrease in step activ- 
ity after inoculation (Hanzlicek et al., 2010). In studies examining social housing, calves were found to be more active when housed in pairs or groups and exhibited an increase in time spent standing (Jensen et al., 1998; Chua et al., 2002). Lying behavior has also been shown to be affected by different housing systems, flooring types, and pen sizes in dairy calves (Webster et al., 1985; Bokkers and Koene, 2001; Hänninen et al., 2005; Færevik et al., 2008). These studies have demonstrated that behavioral measurements can provide quantitative evidence of calf welfare.

Lying behaviors and activity in dairy calves are typically collected via video or direct observation (Webster et al., 1985; Bokkers and Koene, 2001; Hänninen et al., 2005). However, these methods are time consuming. Lying behaviors have been validated in lactating dairy cattle and calves utilizing an accelerometer (HPG; HOBO Pendant G data logger, Onset Computer Corporation, Bourne, MA; Ledgerwood et al., 2010; Bonk et al., 2013). However, the HPG does not measure step activity. Therefore, the objectives of this study were to (1) validate the use of an accelerometer (AT2; AfiTag II, Afimilk Ltd., Kibbutz Afikim, Israel) in dairy calves by comparing step activity, lying bouts, and lying time to the gold standard of video recordings, and (2) to compare the behavioral data from AT2 to the HPG.

The current study was conducted during October 2015 at the Virginia Tech dairy farm. Five unweaned female calves (2 Jersey and 3 Holstein; age $44.6 \pm 3.2$ d) were housed in a group pen on a sawdust pack, which contained a concrete feed alley with an automatic calf feeder and a feed bunk for grain. Calves had access to $12 \mathrm{~L} / \mathrm{d}$ of a $22 \% \mathrm{CP}, 20 \%$ crude fat milk replacer (Amplifier Max, Land O'Lakes Animal Milk Products Co., Shoreview, MN) via an automatic calf feeder (FA Förster-Technik GmbH, Engen, Germany), as well as access to a $22 \% \mathrm{CP}$ calf starter (Intensity $22 \%$ Textured Calf Starter Medicated, Southern States, Richmond, VA).

Video cameras (Canon HF M52, Canon USA Inc., Melville, NY) with 32 GB of internal memory were installed at both sides of the pen. Video was recorded for a 7 -h period during daylight hours for analysis. For each calf, the same 7 -h period of video was analyzed using behavioral analysis software (The Observer XT, Version 12.0, Noldus Information Technology, Leesburg, VA). Video was analyzed continuously by one observer. Using correlations in Excel (Microsoft Corp., Redmond, WA), intra-observer reliabilities $(\mathrm{n}=3$ calves for $2 \mathrm{~h}$ per calf) were found to be 1.00 for both lying time and lying bouts, and 0.93 for step activity. Step activity was defined as the right rear leg lifted off the floor while the calf was standing. A lying bout was defined as the transition from standing to lying, whereas lying time was defined as minutes per period spent lying.

Both AT2 and the HPG were attached to the lateral side of the right rear leg above the metacarpophalangeal joint. For $10-\mathrm{d}$, the HPG recorded the $g$-force and tilt of the $\mathrm{x}-, \mathrm{y}-$, and z-axes at $60-\mathrm{s}$ intervals, and they were wrapped in gauze to provide cushioning and attached to the leg using Vet Wrap (Co-Flex, Andover Healthcare, Salisbury, MA). Output from the HPG was downloaded using graphing and analysis software (HOBOware Lite, Onset Computer Corp., Bourne, MA), and then downloaded to spreadsheets. The AT2 continuously recorded acceleration in the $\mathrm{x}-, \mathrm{y}-$, and zaxes and automatically transmitted these data as step activity and lying behaviors in 15-min intervals to herd management software (AfiAct II, Afimilk Ltd., Kibbutz Afikim, Israel). The AT2 data are cumulative; therefore, the output from AT2 was summarized to match the 24-h segments from the HPG, as well as the 7-h video recordings. The AT2 recorded a lying bout when the calf spent a minimum of 3-min lying down. The AT2 also recorded lying time to the nearest minute, and reported this behavior in 3-min intervals. Lying times not divisible by $3 \mathrm{~min}$ had the remainder added to the next lying bout. The HPG recorded the degree of the y-tilt, which is used to determine standing or lying behaviors, with less than $60^{\circ}$ indicating standing, and greater than or equal to $60^{\circ}$ indicating lying. Using Excel, degrees of y-tilt were converted to either a lying or standing minute, and the change from a standing minute to a lying minute was used to denote a lying bout. Output was also edited to examine the effect of using a 1-min event filter to remove potentially erroneous readings of lying or standing events (Ledgerwood et al., 2010; Bonk et al., 2013). This filter converted behaviors of a 1-min duration back to the original behavior that preceded it. Previous studies in calves have shown an improvement in correlations between the HPG and direct observation for lying time and lying bouts when single lying and standing events were removed, justifying the use of a 1-min event filter (Bonk et al., 2013).

For the first objective, data from the video period were used to determine the accuracy of AT2 and the HPG (PROC REG, SAS 9.4, SAS Institute Inc., Cary, NC) to identify video lying bouts and lying time, and AT2 to identify video steps. Because video was only $7 \mathrm{~h}$, a mixed model containing device and calf was used to determine differences between the HPG, AT2, and video results for lying bouts and lying time, using a Dunnett test with video as the control (PROC GLIMMIX, SAS). A mixed model was also used to determine differences between AT2 and video for step activity. For the second objective, correlations for ly- 
Table 1. Steps, lying bouts, and lying time ( $\mathrm{min}$ ) from 5 calves in a 7-h period recorded either by video, AfiTag II, or the HOBO Pendant G Data Logger, unfiltered and filtered

\begin{tabular}{lcccc}
\hline Item & Video & AT2 & HPG $^{2}$ unfiltered & HPG filtered $^{3}$ \\
\hline Steps & $662 \pm 82$ & $780 \pm 82$ & NA $^{4}$ & NA \\
Lying bouts & $5.0 \pm 0.9$ & $4.8 \pm 0.9$ & $6.4 \pm 0.9$ & $4.8 \pm 0.9$ \\
Lying time & $264 \pm 24$ & $259 \pm 24$ & $265 \pm 24$ & $264 \pm 24$ \\
\hline
\end{tabular}

${ }^{1}$ AT2 = AfiTag II (Afimilk Ltd., Kibbutz Afikim, Israel).

${ }^{2} \mathrm{HPG}=\mathrm{HOBO}$ Pendant G Data Logger unfiltered (Onset Computer Corp., Bourne, MA).

${ }^{3}$ Events $\leq 1$ min from the HPG were converted back to the preceding behavior.

${ }^{4}$ Not applicable.

ing bouts and lying time between the HPG and AT2 were calculated, both overall (PROC CORR, SAS) and within calf (MANOVA of PROC GLM, SAS). Daily lying bouts and lying time were analyzed for differences among AT2 and the HPG, unfiltered and filtered, using a mixed model of device, calf, device $\times$ calf, day, and device $\times$ day $($ PROC GLIMMIX, SAS).

Seven hours of video were analyzed for each of the 5 calves to verify the HPG and AT2 readings, and behaviors are summarized in Table 1. The AT2 was highly correlated with video recordings for step activity, and both accelerometers were highly correlated with video for lying time $(\mathrm{r}=0.99, P<0.01$; Table 2$)$. Lying bouts were also highly correlated between recording methods, with even larger correlations when the data from the HPG were filtered (AT2 with video, 0.99; AT2 with unfiltered and filtered HPG, 0.93 to 1.00; video with unfiltered and filtered HPG, 0.96 to 0.99 ).

Step activity from AT2 exceeded video by $118 \pm 31$ steps $(P=0.02)$. Occasionally during 15 -min lying periods reported from AT2, a small number of steps was counted, suggesting that AT2 will sometimes record leg movement as a step while the calf is lying. This caused AT2 to measure more steps than were counted on video.

The unfiltered output from the HPG reported 1.4 \pm 0.5 more lying bouts per $7 \mathrm{~h}$ than recorded from video $(P=0.03)$, with no other significantly different comparisons. Because no difference was found between the filtered HPG and video, filtering the output improved the accuracy of identifying lying bouts, similar to Bonk et al. (2013). The AT2 also showed no difference in lying bouts when compared with video analysis, providing evidence that AT2 accurately recorded the frequency of lying events. The AT2 reported $5.0 \pm$ 0.8 min less lying time in $7 \mathrm{~h}$ than the video $(P=$ 0.01 ), but no difference was found between the HPG and video. Video is continuous, whereas AT2 records lying time in 3-min increments, and all behaviors are recorded cumulatively. For example, if a calf is lying for 5 min, and the calf stands, AT2 reports 1 lying bout of $3 \mathrm{~min}$. Then, if the calf lies down again for $4 \mathrm{~min}$, AT2 reports a cumulative lying time of 9 min, and 2 lying

Table 2. Overall correlations between video and other recording techniques for step activity, lying bouts, and lying time for 5 calves during a 7 -h period ${ }^{1}$

\begin{tabular}{|c|c|c|c|c|}
\hline Item & Video & $\mathrm{AT} 2^{2}$ & $\mathrm{HPG}^{3}$ unfiltered & HPG filtered ${ }^{4}$ \\
\hline \multicolumn{5}{|l|}{ Step activity } \\
\hline Video & - & & $\mathrm{NA}^{5}$ & NA \\
\hline AT2 & 0.99 & - & NA & NA \\
\hline \multicolumn{5}{|l|}{ Lying bouts } \\
\hline Video & - & & & \\
\hline AT2 & 0.99 & - & & \\
\hline HPG unfiltered & 0.96 & 0.93 & - & \\
\hline HPG filtered & 0.99 & 1.00 & 0.93 & - \\
\hline \multicolumn{5}{|l|}{ Lying time } \\
\hline Video & - & & & \\
\hline AT2 & 0.99 & - & & \\
\hline HPG unfiltered & 0.99 & 0.99 & - & \\
\hline HPG filtered & 0.99 & 0.99 & 0.99 & - \\
\hline
\end{tabular}

${ }^{1}$ All $P<0.01$.

${ }^{2}$ AT2 = AfiTag II (Afimilk Ltd., Kibbutz Afikim, Israel).

${ }^{3} \mathrm{HPG}=\mathrm{HOBO}$ Pendant G Data Logger (Onset Computer Corp., Bourne, MA).

${ }^{4}$ Events $\leq 1$ min from the HPG were converted back to the preceding behavior.

${ }^{5}$ Not applicable. 
Table 3. Correlations between recording techniques for lying bouts and lying time for 5 calves over a 10-d recording period (overall above diagonal, within calf below diagonal $)^{1,2}$

\begin{tabular}{lccc}
\hline Item & $\mathrm{AT}^{3}$ & $\begin{array}{c}\mathrm{HPG}^{4} \\
\text { unfiltered }\end{array}$ & $\begin{array}{c}\mathrm{HPG} \\
\text { filtered }^{5}\end{array}$ \\
\hline $\begin{array}{l}\text { Lying bouts } \\
\text { AT2 }\end{array}$ & - & 0.96 & 0.98 \\
HPG unfiltered & 0.93 & - & 0.95 \\
HPG filtered & 0.96 & 0.91 & - \\
Lying time & - & 0.99 & 0.99 \\
AT2 & -59 & - & 0.99 \\
HPG unfiltered & 0.99 & 0.99 & - \\
HPG filtered & 0.99 &
\end{tabular}

${ }^{1}$ All $P<0.01$.

${ }^{2}$ Within calf correlations after the removal of calf differences in mean bouts or time.

${ }^{3}$ AT2 = AfiTag II (Afimilk Ltd., Kibbutz Afikim, Israel).

${ }^{4} \mathrm{HPG}=\mathrm{HOBO}$ Pendant G Data Logger (Onset Computer Corp., Bourne, MA).

${ }^{5}$ Events $\leq 1$ min were converted back to the preceding behavior.

bouts. This difference in data collection may explain some of the differences noted for lying time.

Table 3 shows the correlations between the HPG and AT2 for lying bouts and lying time as analyzed for a 10 - $\mathrm{d}$ recording period. Correlations within calf have calf variation removed such that a single calf does not have undue influence on the correlation. Overall correlations as well as correlations within calf for lying time were $0.99(P<0.01)$, and were similar for filtered output from the HPG. For lying bouts, filtering the data from the HPG resulted in increased correlations both within calf and overall (0.93 to $0.96 ; 0.96$ to 0.98 , respectively).

During this 10-d period, the unfiltered HPG reported $982 \pm 44 \mathrm{~min} / \mathrm{d}$ of total lying time represented in 24.0 \pm 2.4 lying bouts; filtered HPG reported $979 \pm 44$ $\mathrm{min} / \mathrm{d}$ of total lying time represented in $19.4 \pm 2.4$ lying bouts; and AT2 reported $959 \pm 44 \mathrm{~min} / \mathrm{d}$ of total lying time represented in $20.0 \pm 2.4$ lying bouts (LSM \pm SE per calf). Lying time and lying bouts were similar to those found in previous studies with dairy calves (Chua et al., 2002; Hänninen et al., 2005; Bonk et al., 2013).

Tukey pairwise comparisons were applied to the least squares means of the HPG, filtered and unfiltered, and AT2. Lying bouts recorded by the unfiltered HPG exceeded those of AT2 by $4.0 \pm 0.5$ bouts/d $(P<0.01)$ and exceeded those of the filtered HPG by $4.6 \pm 0.5$ bouts/d $(P<0.01)$. However, the $0.6 \pm 0.5$ difference in lying bouts between AT2 and the filtered HPG was not significant. By removing 1-min behavioral events from the HPG, filtering the output from the HPG resulted in closer agreement with AT2 for lying bouts as AT2 only records a lying bout if the duration is a minimum of $3 \mathrm{~min}$.
The HPG, both unfiltered and filtered, and AT2 differed in lying time. Lying time from AT2 was $23 \pm$ $0.7 \mathrm{~min} / \mathrm{d}(P<0.01)$ less than the unfiltered HPG, and $20 \pm 0.7 \mathrm{~min} / \mathrm{d}(P<0.01)$ less than the filtered HPG. Additionally, the filtered HPG was $3.0 \pm 0.7$ $\mathrm{min} / \mathrm{d}(P=0.02)$ less than the unfiltered HPG. Differences between AT2 and the HPG may be due to AT2 continuously recording lying time, whereas the HPG is providing snapshots of behavior in 60 -s intervals. The difference between the unfiltered and filtered HPG for lying time provides further evidence that a 1-min event filter improves accuracy by removing probable erroneous readings, as found in a previous study (Bonk et al., 2013).

The HPG was recently validated in unweaned calves (Bonk et al., 2013). However, this accelerometer does not measure step activity. The current study is the first to evaluate the use of AT2 attached to unweaned calves. The AT2 was highly correlated with video analysis for step activity, lying bouts, and lying time. Moreover, the AT2 was highly correlated with the HPG for both lying bouts and lying time. Applying a 1-min event filter to the HPG removed spurious readings and improved the accuracy of lying bouts. With high correlations, we declare AT2 as an acceptable tool for measuring step activity, lying time, and lying bouts in unweaned dairy calves. Automated behavioral measurements may have value in determining the effect of different housing and management systems on dairy calves. Technologies may have limitations on their ability to accurately identify behaviors; therefore, it is important to validate the results.

\section{REFERENCES}

Alsaaod, M., C. Römer, J. Kleinmanns, K. Hendriksen, S. Rose-Meierhöfer, L. Plümer, and W. Büscher. 2012. Electronic detection of lameness in dairy cows through measuring pedometric activity and lying behavior. Appl. Anim. Behav. Sci. 142:134-141.

Bokkers, E. A. M., and P. Koene. 2001. Activity, oral behaviour and slaughter data as welfare indicators in veal calves: A comparison of three housing systems. Appl. Anim. Behav. Sci. 75:1-15.

Bonk, S., O. Burnfeind, V. S. Suthar, and W. Heuwieser. 2013. Technical note: Evaluation of data loggers for measuring lying behavior in dairy calves. J. Dairy Sci. 96:3265-3271.

Borderas, T. F., A. M. de Passillé, and J. Rushen. 2008. Behavior of dairy calves after a low dose of bacterial endotoxin. J. Anim. Sci. $86: 2920-2927$.

Chua, B., E. Coenen, J. van Delen, and D. M. Weary. 2002. Effects of pair versus individual housing on the behavior and performance of dairy calves. J. Dairy Sci. 85:360-364.

Dolecheck, K. A., W. J. Silvia, G. Heersche Jr., Y. M. Chang, D. L. Ray, A. E. Stone, B. A. Wadsworth, and J. M. Bewley. 2015. Behavioral and physiological changes around estrus events identified using multiple automated monitoring technologies. J. Dairy Sci. 98:8723-8731.

Færevik, G., K. Tjentland, S. Løvik, I. L. Anderson, and K. E. Bøe. 2008. Resting pattern and social behaviour of dairy calves housed in pens with different sized lying areas. Appl. Anim. Behav. Sci. 114:54-64. 
Fogsgaard, K. K., T. W. Bennedsgarrd, and M. S. Herskin. 2015. Behavioral changes in freestall-housed dairy cows with naturally occurring clinical mastitis. J. Dairy Sci. 98:1730-1738.

Hänninen, L., A. M. de Passillé, and J. Rushen. 2005. The effect of flooring type and social grouping on the rest and growth of dairy calves. Appl. Anim. Behav. Sci. 91:193-204.

Hanzlicek, G. A., B. J. White, D. Mosier, D. G. Renter, and D. E. Anderson. 2010. Serial evaluation of physiologic, pathological, and behavioral changes related to disease progression of experimentally induced Mannheimia haemolytica pneumonia in postweaned calves. Am. J. Vet. Res. 71:359-369.

Itle, A. J., J. M. Huzzey, D. M. Weary, and M. A. G. von Keyserlingk. 2015. Clinical ketosis and standing behavior in transition cows. J. Dairy Sci. 98:128-134.

Jensen, M. B. 2012. Behaviour around the time of calving in dairy cows. Appl. Anim. Behav. Sci. 139:195-202.
Jensen, M. B., K. S. Vestergaard, and C. C. Krohn. 1998. Play behaviour in dairy calves kept in pens: The effect of social contact and space allowance. Appl. Anim. Behav. Sci. 56:97-108.

Khanal, A. R., J. Gillespie, and J. MacDonald. 2010. Adoption of technology, management practices, and production systems in US milk production. J. Dairy Sci. 93:6012-6022.

Ledgerwood, D. N., C. Winckler, and C. B. Tucker. 2010. Evaluation of data loggers, sampling intervals, and editing techniques for measuring the lying behavior of dairy cattle. J. Dairy Sci. 93:5129-5139.

Webster, A. J. F. C. Saville, B. M. Church, A. Gnanasakthy, and R. Moss. 1985. The effect of different rearing systems on the development of calf behaviour. Br. Vet. J. 141:249-264. 